\title{
A systematic review of randomised controlled trials, non-randomised controlled trials and observational studies to ascertain the role of pollen-specific immunotherapy in improving clinical outcomes in pollen-food (ORAL ALLERGY) syndrome
}

\author{
Priya Bowry \\ From 3rd WAO International Scientific Conference (WISC) 2014 \\ Rio de Janeiro, Brazil. 6-9 December 2014
}

\section{Background}

Pollen Food(Oral allergy) Syndrome (PFS) is a food allergy which is caused by cross-reactivity between inhalant pollen allergens and food allergens, causing mild to severe symptoms upon ingestion of the cross-reacting foods. PFS has a high and increasing prevalence in pollen-allergic patients. The role of pollen-specific immunotherapy in improving clinical outcomes for patients with PFS has not been established. To date, there are no systematic reviews which have been identified in the background research in this field. Aim of the review was to evaluate the evidence and determine whether pollenspecific immunotherapy clinically improves symptoms of PFS in pollen-allergic patients.

\section{Methods}

This review was undertaken in accordance with the Cochrane Handbook for Systematic Reviews and PRISMA. Comprehensive literature search was conducted to identify suitable studies including randomised controlled trials (RCTs), observational studies and nonrandomised trials (NRCTs) which investigated the role of a pollen-specific immunotherapy for a minimum period of 1 year in the clinical improvement of PFS in pollen-allergic patients. Quality assessments were made for each study using two instruments to ensure methodological rigour. Raw outcome data was extracted and

The Allergy Clinic, Kenya 
clinical outcomes for PFS patients. However, the inadequacies of the reported trials analysed limit the reliability of these findings. Further research is warranted on the basis of these results, using robust clinical studies.

- Convenient online submission

- Thorough peer review

- No space constraints or color figure charges

- Immediate publication on acceptance

- Inclusion in PubMed, CAS, Scopus and Google Scholar

- Research which is freely available for redistribution 